\title{
Energy Saving Options in Sugar Production
}

\author{
Sergey Melnik, Vladimir Nikulshin and Alla Denysova* \\ Odessa National Polytechnic University, Odessa, Ukraine
}

Received: June 01, 2018; Published: June 13, 2018

*Corresponding author: Alla Denysova, Odessa National Polytechnic University, Odessa, Ukraine

\section{Mini Review}

Energy consumption in a sugar production is mainly in the form of heat for technological processes: evaporation of water from the juice, boiling, heating the chips to conduct the diffusion process, heating the juices during the cleaning process, and also to compensate for heat losses through the surface of equipment. At the same time, specific energy consumption of a sugar production is rather big and can reach up too $1500 \mathrm{~kJ} / \mathrm{kg}$. Our investigations as well as results of others authors allowed to form the following three groups of energy-saving options:

\section{Options that use secondary energy resources:}

a) Use of hot juice for yellow sugar preparing

b) Use of a secondary steam

c) The heating of the vacuum apparatus by the mantle vapor

d) Use of the heat of condensates to heat the diffusions flows

e) Use of condensate for defecation of juice

f) Use of condensate for heating of the 1st saturation juice before filtration

g) Use of condensate to heat the juice before the 2nd saturation and juice before the evaporator

h) Use of saturation gases heat

i) Use of de-ammoniated condensates and pulp water for feeding diffusion installation

\section{b. Options that change the parameters of flows:}

a) Compression of the secondary steam

b) Decrease of the diffusion juice extraction temperature

c) Decrease of defecation temperature in the process of the 1st and 2nd carbonation

d) Use of a non-condensing gases heat e) Decrease flow of the return unfiltered juice of the 1st carbonation

f) Use of a sugar cleaning combination

g) Increase of vacuum in vacuum devices due to reduction of air sucks

h) Improvement of the condensation unit operation

i) Reduction of aerodynamic losses in pipelines

c. Options based on constructive solutions (structural changes):

a) Use of a hydrodynamic evaporator

b) Transfer of a steam extraction to final corps of evaporation line

c) Increase the number of crops in the evaporation line

d) Improvement of the circulation of juice in the vacuum apparatus by the injection of steam, ammonia gases, air

e) Heating of syrup in the plate heaters

f) Reduction of the steam flow from the last corps to the condenser

g) Improvement of thermal insulation of equipment and pipelines

It is easy to see that the identified energy-saving options can be used as a basis for the subsequent search $\mathrm{f}$ rational variants of sugar production schemes. However, it is clear that implementation of most of them (for example, the steam compression, the transfer of steam extraction to final crops, the increase the number of crops, etc.) will require additional capital investments. Therefore, the final decision about the use of specific energy-saving options requires an appropriate thermo-economic approach which, as is known, involves a thermodynamic analysis of the system with the calculation of the of streams exergy and exergy losses in the elements of sugar 
production and in the system in whole. It is convenient to carry out the thermodynamic analysis of on technological processes, which are cyclically repeated in technology of sugar production is, into the following characteristic groups: initial preparing of product, syrup heating, evaporation of syrup, syrup collection, product filtration, chemical processing of products etc.

In the initial preparing of product, the greatest loss of exergy $(187 \mathrm{~kW})$ falls on the process of obtaining affinity sugar with a minimum value of the degree of thermodynamic perfection 0.5 . This is due to dissipative losses of centrifugation processes, mechanical separation and grinding, diffusion, in which energy is spent on the equipment drives. In processes of syrups heating the exergy losses caused to heat transfer irreversibility at sufficiently high temperature differences, and the dissipative losses of the product transportation process in the subsequent processing steps. The largest losses of exergy ( $93 \mathrm{~kW}$ ) fall on the process of heating the syrup of affinity sugar at a low value of the degree of thermodynamic perfection 0.77 . For syrup evaporation the greatest exergy loss (kW 1451) occur in the process of primary refined (as well as a low value of 0.55 degree thermodynamic perfection), which results to a large heat flows and a irreversibly of heat transfer processes at high temperature differences. In the processes of collecting syrups loss of exergy caused by dissipation in transportation of the product from several locations with subsequent mixing and direct losses of a heat to the environment from the equipment due to imperfect thermal isolation. The largest losses of exergy $(10 \mathrm{~kW})$ fall on the process of collecting the syrup 2 product at a sufficiently high value of the degree of thermodynamic perfection 0.92 .

During filtration, the greatest loss of exergy ( $30 \mathrm{~kW}$ ) falls on the process of filtering the syrup before sulphation at a sufficiently high value of the degree of thermodynamic perfection 0.89 . This is due to the dissipative processes during filtration and the low quality of filtration material. In the processing of products, the greatest loss of exergy ( $31 \mathrm{~kW}$ ) falls on the process of sugar raw affinity with a minimum value of the degree of thermodynamic perfection of 0.85 , which is caused by the irreversibility of physicochemical processes of purification of raw sugar. In addition, dissipative losses of the processes of pumping this product into subsequent technological stages are added. As follows from the consideration of the results for system of sugar production as a whole given in (Table 1), the greatest exergy losses are observed during the process of syrup evaporation (more than $70 \%$ of the exergetic losses of the whole process of sugar production). In addition, these processes are also characterized by the lowest degree of thermodynamic perfection from all the processes under consideration (0.54), therefore, for these processes have been given the most attention.

Table 1.

\begin{tabular}{|c|c|c|c|c|c|}
\hline No. & $\begin{array}{c}\text { Groups of production } \\
\text { processes }\end{array}$ & $\begin{array}{c}\text { Exergy } \\
\text { at the input, } \mathbf{k W}\end{array}$ & $\begin{array}{c}\text { Exergy } \\
\text { at the output, } \mathbf{k W}\end{array}$ & $\begin{array}{c}\text { Exergy losses, } \\
\mathbf{k W}\end{array}$ & $\begin{array}{c}\text { The degree of thermodynamic } \\
\text { perfection }\end{array}$ \\
\hline 1 & Initial preparing & 1022 & 665 & 357 & 0.65 \\
\hline 2 & Syrups heating & 1034 & 831 & 203 & 0.8 \\
\hline 3 & Evaporation of syrups & 8236 & 4448 & 3788 & 0.54 \\
\hline 4 & Syrups collecting & 309 & 284 & 25 & 0.92 \\
\hline 5 & Filtration of syrups & 1122 & 1020 & 84 & 0.91 \\
\hline 6 & Processing of products & 899 & 815 & 720 & 0.91 \\
\hline 7 & Sugar cleaning & 1669 & 949 & 5279 & 0.57 \\
\hline & Total & 14291 & 9012 & & 0.63 \\
\hline
\end{tabular}

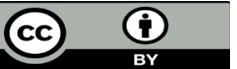

This work is licensed under Creative Commons Attribution 4.0 License

Submission Link: https://biomedres.us/submit-manuscript.php

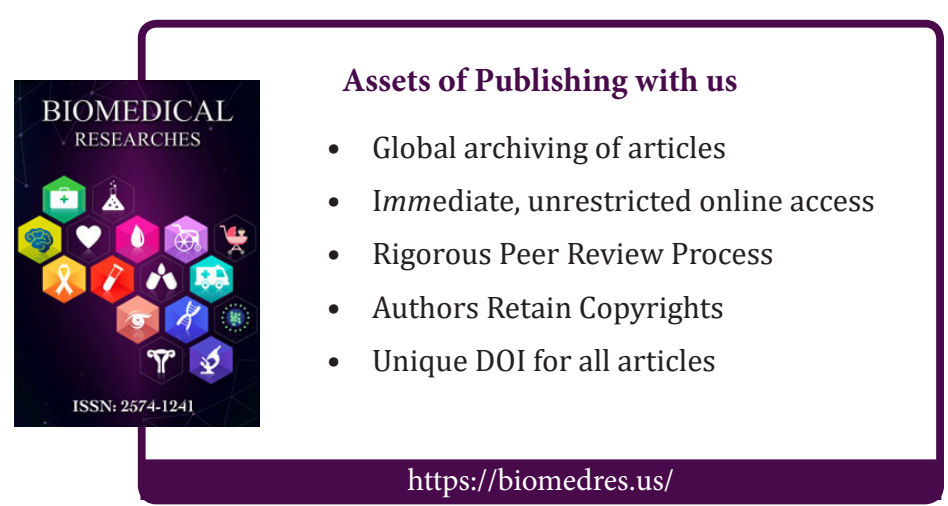

